\title{
In Search of SecondLife Nirvana
}

\author{
Doug Vogel \\ Department of Information Systems \\ City University of Hong Kong \\ Hong Kong, P. R. China \\ Maxwell Guo, Phil Zhou, Stella Tian and Jacky Zhang \\ USTC-CityU Joint Research Center \\ Suzhou, P.R. China
}

\author{
isdoug@cityu.edu.hk maxwell@mail.ustc.edu.cn \\ zzyun@mail.ustc.edu.cn stellat@mail.ustc.edu.cn \\ xizhang@mail.ustc.edu.cn
}

\begin{abstract}
Pedagogically-driven support for groups is a continuing challenge as we move forward in embracing technology in an ever changing educational environment. SecondLife

(www. SecondLife.com) is a virtual environment that is receiving global attention and recognition. In this paper, we compare SecondLife to other group support technologies through an extended Technology Acceptance Model (TAM) lens. The environment chosen is a virtual team space in which an online book is produced through interactions between graduate students in Hong Kong and the Netherlands. A portfolio of technologies including email, forums, videoconferencing, SecondLife, and MSN was provided for team support and subsequently evaluated. Results indicate that SecondLife (at least in its current incarnation) is likely to need some reincarnation priorto ascent to Nirvana. In that sense, it is a goal hoped for but yet to be attained in supporting teams. Suggestions for development and directions for fut ure research are provided. Conclusions are drawn.
\end{abstract}

Keywords: virtual worlds, technology acceptance, TAM, group support, pedagogy, Second Life

\section{Introduction}

Teaching and learning are undergoing a paradigm shift not only with respect to constructive alignment with student needs, but also to the creation of an extended learning environment outside traditional classroom walls. Teams are a mainstay and bedrock element of a broad range of

Material published as part of this publication, either on-line or in print, is copyrighted by the Informing Science Institute. Permission to make digital or paper copy of part or all of these works for personal or classroomuse is granted without fee provided that the copies are not made or distributed for profit or commercial advantage AND that copies 1) bear this notice in full and 2) give the full citation on the first page. It is permissible to abstract these works so long as credit is given. To copy in all other cases or to republish or to post on a serveror to redistribute to lists requires specific permission and payment of a fee. Contact Publisher@ InformingScience.org to request redistribution permission. teaching and learning activities. Comprehensively supporting teams technologically, especially in global contexts, is not easy but can be exceptionally rewarding for all involved.

SecondLife (www. SecondLife.com) is a virtual environment (within which reallife experiences can be attained) that has a range of support opportunities for teams including aspects of visualization and sense of presence, as well as text 
and audio interaction. However, little is known about the reception of SecondLife in support of virtual team activities, especially in conjunction with use of a portfolio of othertechnologies.

The Technology Acceptance Model (T AM) (Davis, 1989) and its successor, T AM2 (Venkatesh \& Morris, 2000), have been widely utilized in underst anding the reaction of individuals to different technologies. T AM (and T AM2) look particularly at aspects of perceived ease of use and usefulness. Extensions of T AM and T AM2 go beyond considerations of gender and experience to include aspects of enjoyment and interaction capacity on the road to understanding user attitude and intention, thus leading to user behaviour in team contexts.

The Hong Kong / Netherlands (HKNet) project has, over the past ten years, provided a structured environment in which virtual teams experience a variety of synchronous and asynchronous technologies. Teams go through a set of pedagogically-driven activities over an eight week period, resulting in delivery of an online electronic book. HKNet has been recognized for innovation in education (e.g., Genuchten \& Vogel, 2007; Genuchten, Vogel, Rutkowski, \& Saunders, 2005). The project provides a platform within which aspects of the impact and implications of group support technologies can be examined.

In this paper, we compare SecondLife to other group support technologies through an extended TAM lens in the most recent HKNet project (http://bohknet.tm.tue.nl/index.html). A portfolio of technologies including email, forums, videoconferencing, SecondLife, and MSN was provided for team support and subsequently evaluated. Results are presented and discussed. Suggestions for development and directions for fut ure research are provided. Conclusions are drawn.

\section{Background}

Teaching and learning is undergoing a paradigm shift not only with respect to constructive alignment with student needs, but also to the extended learning environment out side traditional classroom walls becoming salient. E-learning is key to this transition and sustaining educational presence in life-long learning. Currently, there are many hurdles where a consistent problem is that much of what we have in terms of technological support is not well-understood, nor is it integrated in a fashion that can synergize extended use by a large number of educators and students.

Teams are a mainstay and bedrock element of a broad range of teaching and learning activities. Comprehensively supporting teams technologically, especially in global contexts, is not easy but can be exceptionally rewarding for all involved. A common problem in virtual teams is lack of presence and difficulty in sustaining interaction and developing trust, especially in multi-cultural circumstances. This is further complicated by the often fragmented nat ure of team support, both in terms of pedagogically-driven protocols and technological support. Seamless integration with a focus on scalability and sustained effort is paramount.

Technological support for teams has been conducted under a collection of names, such as Group Decision Support Systems, Electronic Meeting Systems, Group Negotiation Support Systems, Computer Mediated Communication Systems, and Computer Supported Collaborative Work (e.g., Grudin, 1991). We collectively recognize this area of study as Group Support Systems (GSS). A variety of feature categorizations and frameworks has been proposed (e.g., DeSanctis $\&$ Gallupe, 1987). There has been extensive research examining GSS application in both laboratory and field settings (e.g., Dennis, George, Jessup, Nunamaker, \& Vogel, 1988; Kwok, Ma, \& Vogel, 2002; Nunamaker, Briggs, Mittleman, Vogel, \& Balthazard, 1997; Qureshi, Liu \& Vogel, 2006; Vogel, Nunamaker, Martz, Grohowski, \& McGoff, 1990). GSS has also been evaluated in distributed contexts (e.g., Valacich, George, Nunamaker, \& Vogel, 1994) with special attention to processes (e.g., Dean, Lee, Orwig, \& Vogel, 1995; Dean, Orwig, \& Vogel, 2000). Stahl (2006) has focused particularly on computer support for building collaborative knowledge. 
GSS application has recently focused on virtual groups (e.g., Lu, Watson-Manheim, Chudoba, \& Wynn, 2006; Maznevski \& Chudoba, 2000; Saunders, Van Slyke, \& Vogel, 2004). Piccoli and Ives (2003) examine aspects of trust and the unintended effects of behavior control in virtual teams with US participants, and note the sensitive nature of degree of control in affecting team interactions. Griffith, Sawyer, and Neale (2003) point to difficulties inherent in balancing distribution and transfer of individual and organizational knowledge in virtual teams. Robey, Khoo, and Powers (2000) particularly deal with varied use of technology in international virtual team contexts. Kanawatt anachai and Yoo (2007) examine aspects of knowledge coordination. GSS has also long been used in supporting university groups and researchers with technology, in both local and distributed contexts (e.g., Alavi, Yoo, \& Vogel, 1997).

\section{HKNet}

The HKNet (Hong Kong and the Netherlands) project began in 1998 with the universities of Eindhoven and Hong Kong. The number of students has ranged from 65 to 180, depending on class sizes at the various sites. Each HKNet team typically consists of eight to ten students in two to four locations. The team is assigned an IT-related topic such as software in the car industry and household robotics which students approach from different geographical and cultural perspectives. The structured process consists of several divergent and convergent activities that take place over eight weeks. The different groups produce a Web site for discussing their topics from European and Asian perspectives. The web sites are integrated into an electronic book.

This process involves a multi-year effort in which participants use the results of previous years as input for the current year. In week 1, the participants are formed into teams who first evaluate the previous years' websites. Subsequent weeks focus on identification of research questions in association with their selected topic and creation of a development and delivery plan. In week 6, students need to deliver a Web site that discusses their topic. Then, in week 7, they must integrate a chapter into the project's electronic book (http://bohknet.tm.tue.nl/index.html).

The technologies used in the most recent HKNet project include e-mail, forums (Blackboard), videoconferencing, SecondLife and a common online chat tool (MSN). The students are free to choose which tools to use (and how) to create the Web site. HKNet classroom instructors address group dynamics and management issues to accelerate the experiential learning, including planning, work breakdown, information overload, and knowledge management. Experiences overthe years have been systematically recorded (e.g., Rutkowski, Vogel, Bemelmans, \& Genuchten, 2002; Rutkowski, Saunders, Vogel, \& Genuchten, 2007; Vogel et al. 2001).

There is often confusion on when the word "which" should be used to introduce a clause and when "that" should be used and when they should be separated from the rest of the sentence by commas. In this journal we will follow these guidelines.

\section{SecondLife}

Virtual worlds have appeared in educational research since the early 1990s (e.g., Hughes \& Moshell, 1997) and are now becoming popular in universities and companies as a tool to create virtual learning environments. For example, Chinese virtual worlds in various stages of development and implementation include HiPiHi, Shanda, uWorld from UOneNet, Entropia, Frenzoo, and Novoking. On a global level, SecondLife, is attract ing special interest from educational and business fields. SecondLife (from Linden Research) is an online virtual world where the content is built and owned by its users, providing tools and guidance for manipulating the environment and allowing action scripting, object construction and an economy that supports the creation of virtual environments (Hobbs, Gordon, \& Brown, 2006). SecondLife has characteristics both as a 
distributed communication tool and as an entertainment environment, and has relevance in both online collaborative learning and online business fields.

SecondLife (www. SecondLife.com) is a virtual environment within which real-life organizational experiences can be attained. It is an opportunity space (not a deterministic space) limited only by imagination. Admission is free and learning opportunities abound. SecondLife has representations of a wide variety of existing global organizations (e.g., car dealerships, computer industry, insurance companies and financial institutions), in addition to newly created entrepreneurships whose only limitation is the imagination of the creators. Governments also have a presence on SecondLife (e.g., the Swedish embassy). SecondLife has a currency (i.e., Linden dollars) that enables participants to engage in business transactions. There are currently over 30 universities with a SecondLife presence and communities of practice.

The Alpine Executive Center, located on the MeetingSupport sim in Second Life, was used in 2007 to support HKNet. Within an alpine ski village, surrounded by snow-covered mountains and tucked away deep inside the mountain, lies an advanced meet ing facility where real-world activities take place in a virtual environment. A main amphitheater is accessed via a train that goes deep inside the mount ain complex or by a walk along the frozen ice skating pond, or by teleport from the visit or landing area. An auditorium supports large groups in plenum for presentations and moderated discussions. A host of additional facilities exist to support teams. For example, teams can meet at one of the ten gathering spots around the Alpine village, including mountain huts with interactive screens and scenic lookouts. Participants also have opport unities to explore, shop, play, go ice skat ing or just have fun together riding the chair lift and using the timed downhill and slalom ski runs.

\section{Research Approach}

In this study, we focus on respondents' acceptance and use of SecondLife (SL) as a communication tool. We incorporate core constructs of the Technology Acceptance Model (T AM) championed by Davis (1989) based on the Theory of Reasoned Action (TRA), as illustrated in Figure 1. According to Davis (1989), Percei ve usefulness (PU) is "the extent to which a person believes that using a particular technology will enhance her/his job performance"; Pe rcei ved ease of use (PEOU) is the "degree to which a person believes that using the system will be free from effort." T AM has been used extensively for understanding and predicting user accept ance of information technology (e.g., Bhat tacherjee, 2001; Gefen, Karahanna, \& Straub, 2003; Ha, Yoon, \& Choi, 2007; Hsu \& Lu, 2004; Hwang, 2005; Koufaris, 2002; Lou, Luo, \& Strong, 2000; Mellarkod, Appan, Jones, \& Sherif,, 2007; Wu \& Liu 2007), and has been empirically demonstrated successful in prediction system use (Hu \& Chau,1999; Legris, Ingham, \& Collerette, 2003).

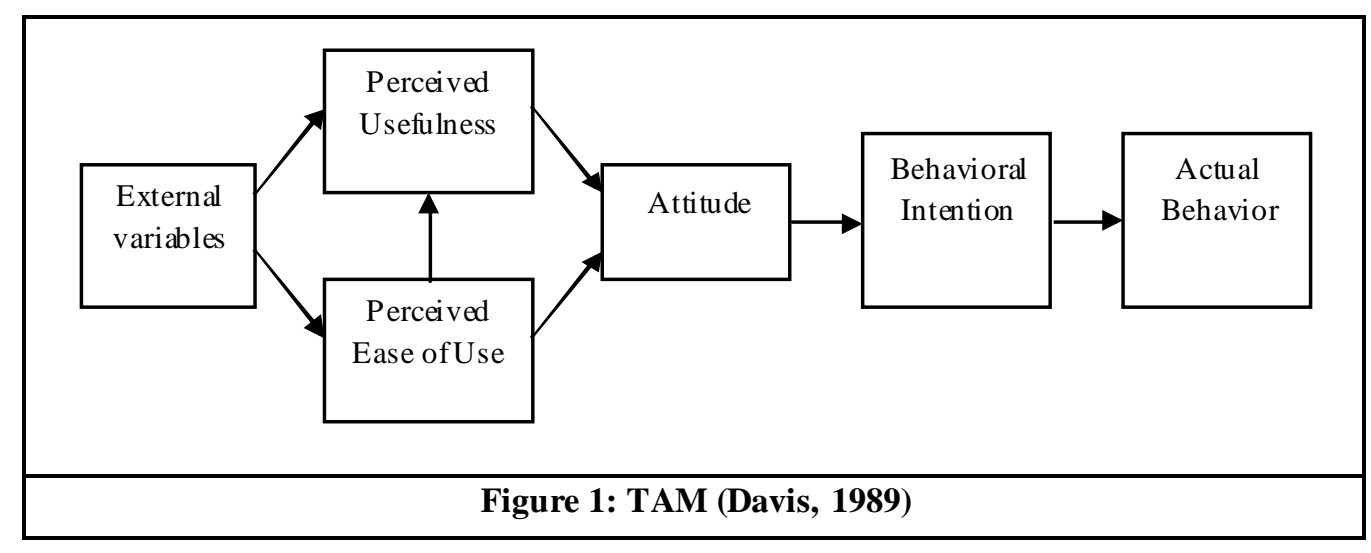


However, researchers suggest that the two dimensions in TAM, perceived usefulness (PU) and perceived ease of use (PEOU), are too narrow and shine light on only a part of technology acceptance and use. Further, they believe that more factors from other aspects (such as emotional reactions and social factors) should be included to explain accept ance more consistently and comprehensively (Agarwal \& Prasad, 1997; Legris et al., 2003; Lucas \& Spitler, 1999; Szajna, 1996). Thus, T AM2 (by Venkatesh \& Morris, 2000, see Figure 2) has been proposed to better explain the accept ance and use of IT applications. Factors including subjective Norms ( $\mathrm{SN}$ ) and moderators or control variables, including gender and experience, are identified. Empirical studies (e.g., Hsu \& Lu, 2004) have been carried out to demonstrate the relevance of TAM2 in predicting IT acceptance.

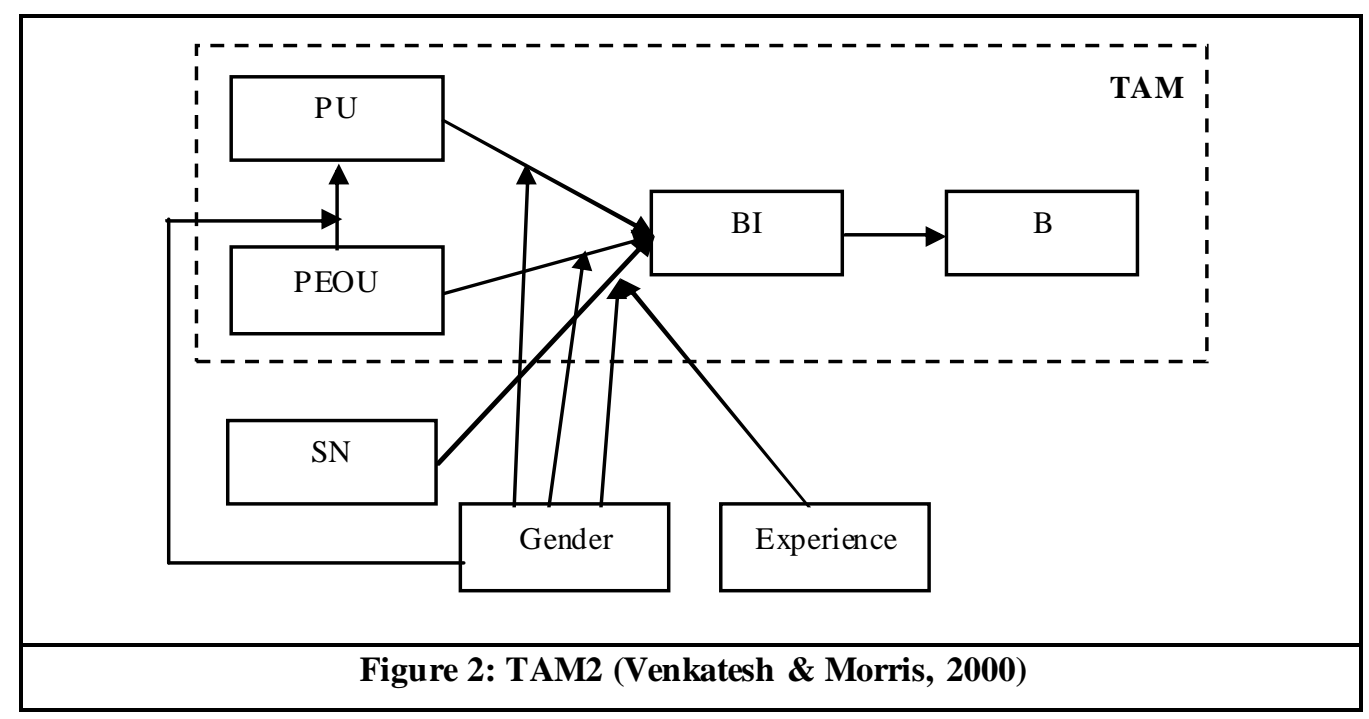

Subjective norm (SN) is the degree to which an individual believes that people who are important to herhim think that she/he should perform the behavior in question (Fishbein \& Ajzen, 1975; Venkatesh \& Morris, 2000). In the technology domain, social influences (from both peer and superior sides) have been shown to be strong determinants of subjective norms (Mathieson, 1991; Taylor \& Todd, 1995). Such circumstances are particularly important in the context of virtual teams. Inte raction Capacity (IC) as a particular issue was include do tap differences in media richness relevant to team interactions. In this sense, capacity to transmit multiple cues (e.g., body language and voice tone) and emotions (e.g., anger, happiness and excitement) as well as functionality relevant for interaction and an appropriate style of design (e.g., an attractive interface) were added as measures. Percei ve d enjoyment (PEN) is the extent to which the activity in question is perceived to be enjoyable, apart from any performance consequences or utilitarian considerations (Koufaris, 2002) and was added to take into consideration aspects extending beyond work. PEN has been shown to have positive effects on intention (Ha et al., 2007; Hsu \& Lu, 2004).

\section{Results}

A voluntary online survey was given in week 3 after students had experienced each of the technologies under examination, i.e., email, forums, videoconferencing (VC), SecondLife (SL) and MSN. The developed questionnaire (seethe Appendix) reflects measures for the previously noted constructs using a 7-point Likert scale from "strongly disagree" to "strongly agree." Atotal of 48 participants (55\%) responded. The following Figures illustrate survey results. 
As quickly recognized in Figure 3, MSN was dominant in terms of perceived usefulness. The MSN-supported quickness, ease and efficiency were to be expected. Somewhat surprisingly, effectiveness ratings were also high in spite of MSN leanness. Videoconferencing was seen as considerably less useful on all measures but was also scheduled and time-limited, relatively speaking. The high ratings for email are attributable to familiarity and support for asynchronous interaction which was especially important given the seven hour time difference between Hong Kong and the Netherlands. Forums were perceived useful for the same reason. SecondLife fared particularly poorly on all measures. ANOVA with Tukey followup revealed that the mean response to SecondLife was significantly less $(\mathrm{p}=.00)$ compared to any othertechnology examined. As one participant noted, "No one is there when I login SL."

\section{Perceived Usefulness}

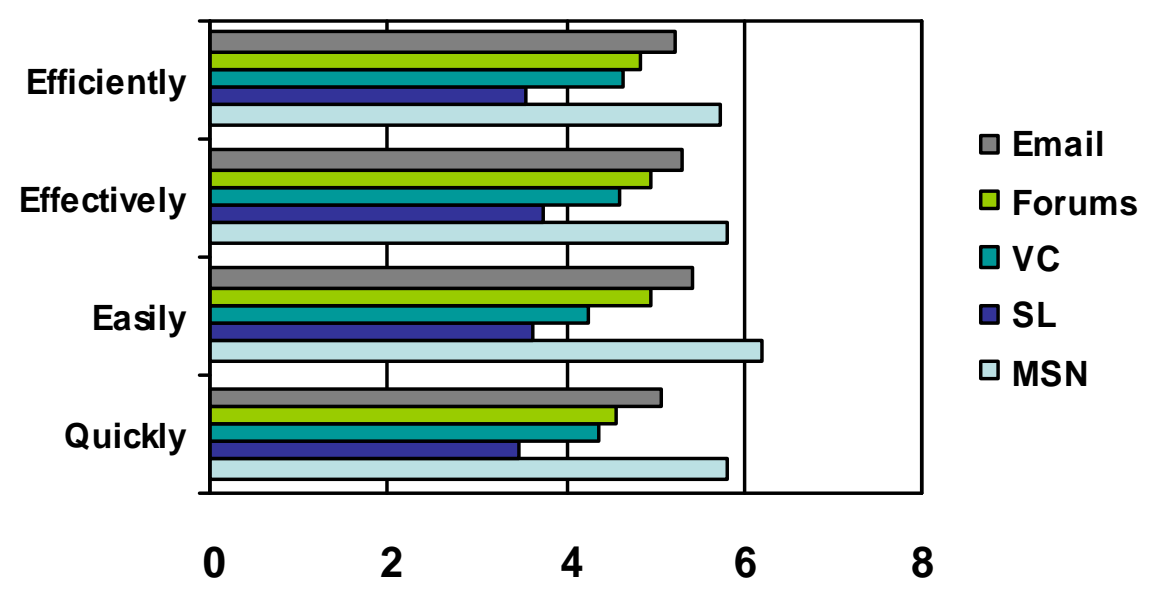

Figu re 3: Percei ved Usefulness

Perceived ease of use, as illustrated in Figure 4, followed patterns similar to perceived usefulness for essentially the same reasons. Email and MSN are even more dominant as one might expect given participant familiarity and broad-based use. Here again, ANOVA with Tukey followup revealed that the mean response to SecondLife was significantly less $(\mathrm{p}=.00)$ compared to any othertechnology examined. 


\section{Perceived Ease of Use}

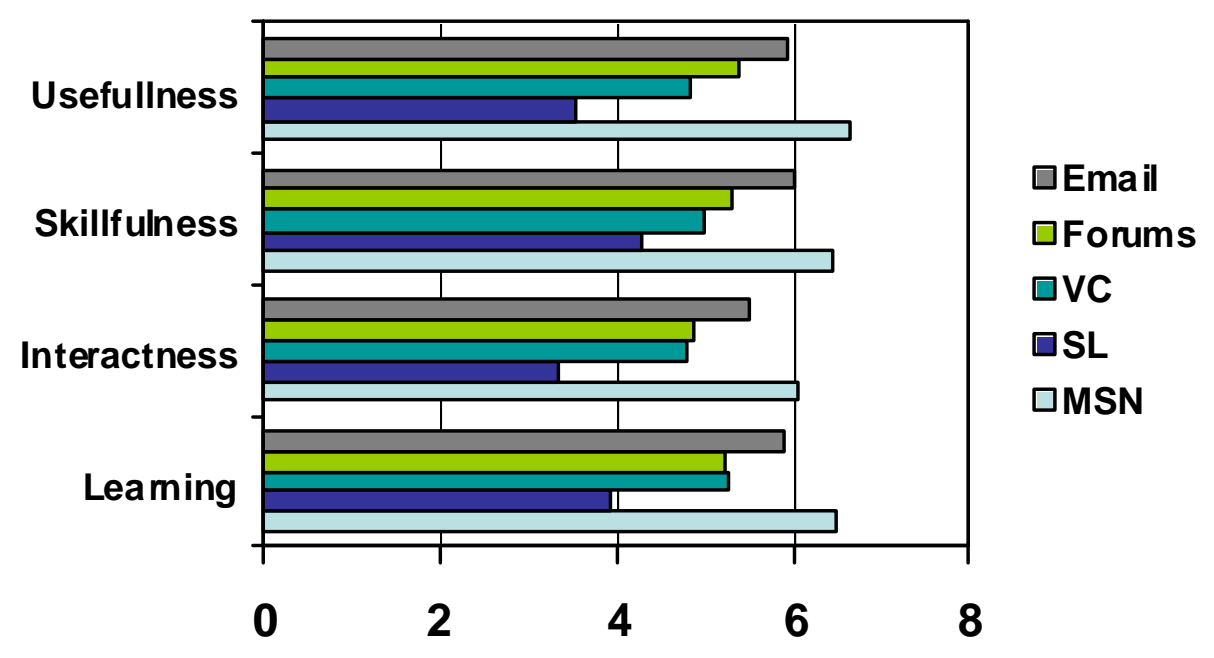

Figu re 4: Perceived Ease of Use

Not surprisingly, as illustrated in Figure 5, attitude generally follows perceived usefulness and ease of use given their T AM precedence noted in Figure 1. The exception is the enhanced desirability of videoconferencing attributable to its high degree of sense of presence and degree of interaction realism, courtesy of being a rich media. ANOVA with Tukey followup revealed that the mean response to SecondLife was significantly $(\mathrm{p}=.00)$ less compared to any othertechnology examined other than forums ( $\mathrm{p}=.08)$.

\section{Perceived Team Attitude}

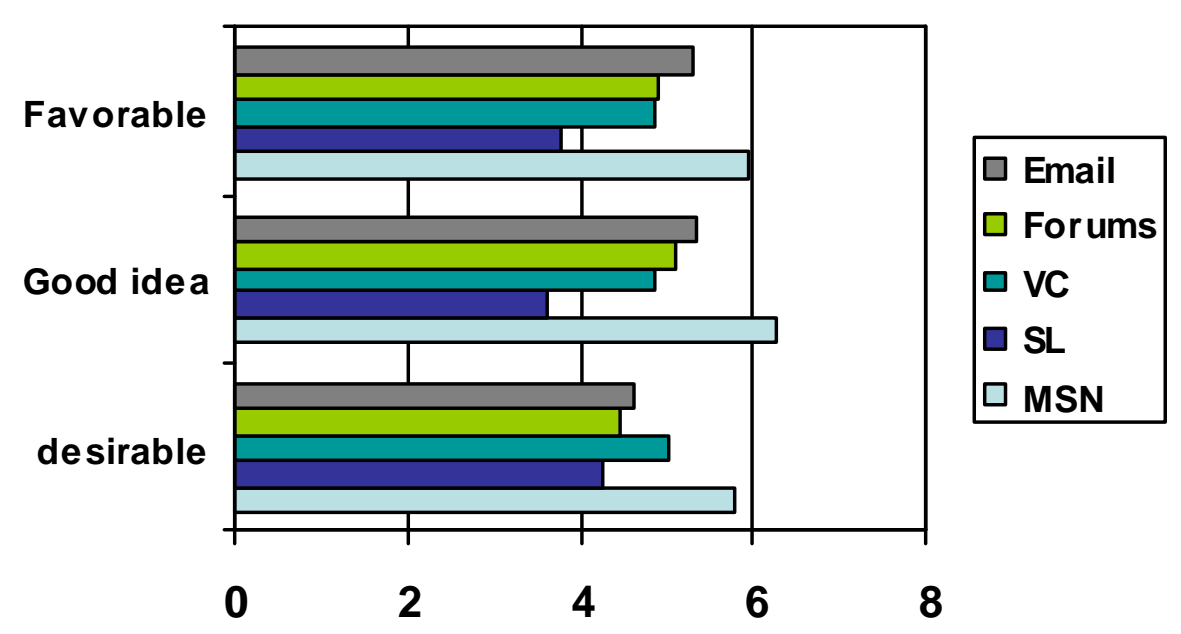

Figure 5: Perceived Team Attitude

Perceived team enjoyment as illustrated in Figure 6, begins to recognize some of the distinctive characteristics of other less lean media. Here we can see a relative increase of SecondLife as well as videoconferencing, especially in terms of fun. ANOVA with Tukey followup revealed that the mean response to SecondLife was significantly less $(\mathrm{p}=.01)$ compared only to MSN and not sig- 
nificantly different to the other technologies (i.e., videoconferencing, email and forums). However, MSN still rules supreme on all measures, perhaps as a reflection of its ease of use and perceived usefulness.

Interaction capacity, Figure 7, illustrates special interest in videoconferencing, and SecondLife to a lesser extent, especially in terms of having an appropriate style of design (e.g., an attractive interface) for interaction. Here, ANOVA with Tukey followup revealed that the mean response to SecondLife was significantly less $(p=.00)$ compared to forums and email and MSN ( $p=.03)$ but not significantly different to videoconferencing. Videoconferencing is dominant in terms of ability to transmit emotions (such as anger, happiness and excitement) and capacity to transmit multiple cues (such as body language and voice tone). This is not surprising given its multi-media nat ure. SecondLife exhibited similar characteristics but was not able to overcome the overall dominance of MSN.

Overall, intention to use as illustrated in Figure 8 speaks well for simplicity and the general dominance of ease of use and usefulness of MSN and email. SecondLife rates poorly by comparison while forums and videoconferencing assume a middle-level existence. ANOVA with Tukey followup revealed that the mean response to SecondLife was significantly less $(p=.00)$ compared to MSN and email as well as videoconferencing $(\mathrm{p}=.01)$ and even forums $(\mathrm{p}=.05)$ completing the sweep of negative reaction.

\section{Perceived Team Enjoyment}

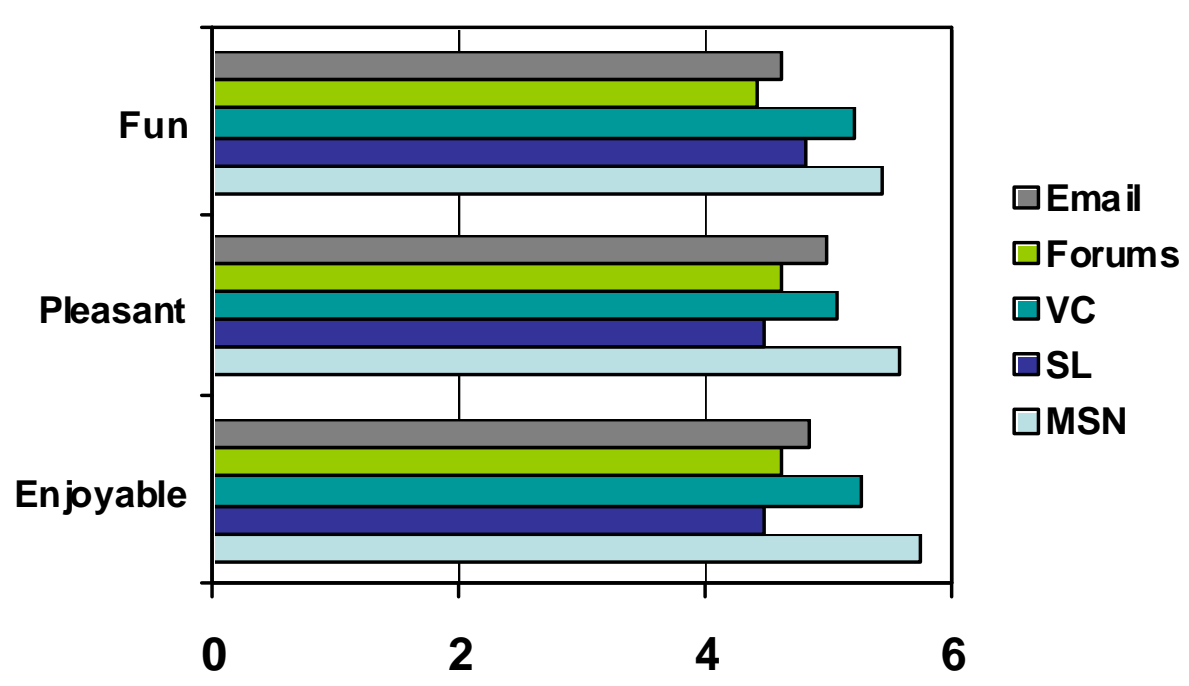

Figure 6: Perceived Team Enjoyment 


\section{Interaction Capacity}

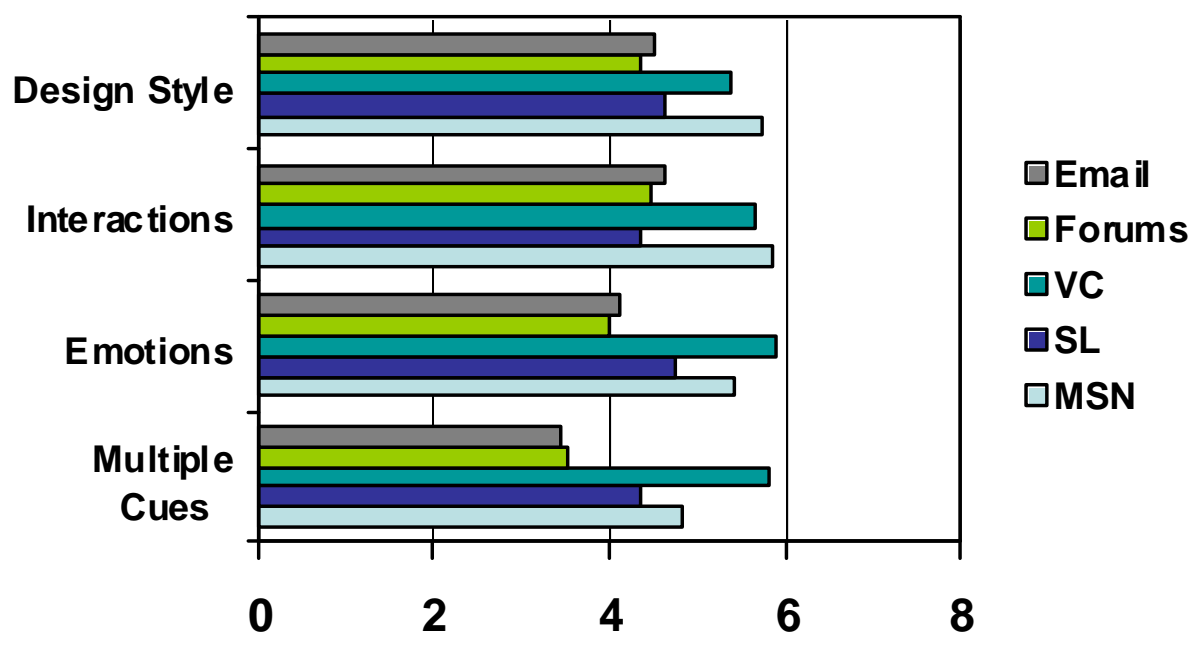

Figure 7: Interaction Capacity

\section{Intention to Use}

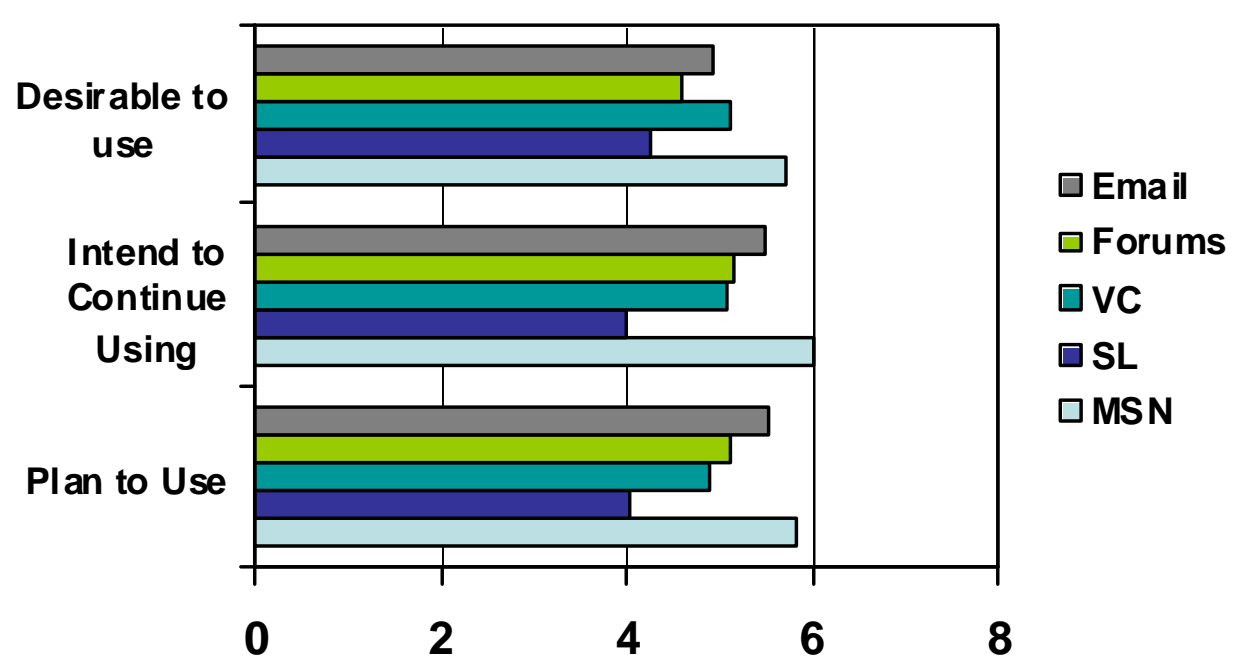

Figure 8: Intention to Use

\section{Discussion}

Clearly, SecondLife has not fared well under the lens of T AM and TAM2. Part of the reason lays in the general difficulty of loading and using the software. SecondLife is updated weekly, places high demands on bandwidth and is prone to frequent crashes and general poor performance, relative to more established technologies. The interface is not particularly intuitive. As one participant noted, "We could only change dressings, walking around and always get lost in it, I can not control it." 
Further, it may be that TAM is a poor lens with which to examine SecondLife in that it only deals with a relatively small number of traditional areas, e.g., perceived usefulness and ease of use that are not distinctions of SecondLife in its combined work and play motif. Indeed, our results provide some support in that regard, noting the relatively higher ratings for SecondLife in terms of perceived team enjoyment and interaction capacity. However, all was not that favorable for SecondLife in this regard. As one participant noted, "I do not view SL as a game. It is funny, has lots of features, but we do not need these features, MSN is enough."

Measures of SecondLifetypically had twice the amount of variance relative to other technologies examined, point ing to differences within the population surveyed. Women significantly rated SecondLife higher than men, and older participants were significantly more pleased which we attribute to novelty and lack of interest in more advanced gaming environments (tending towards more violence with less business focus). As one participant noted, "SL is interesting, has lots of features, but I have no time to explore them, although I like them. But we will try these features in the future."

SecondLife, under the best of circumstances, still has much room (and need) to grow beyond issues of technical stability. The lack of avat ar realism, compared to popular online games, is a drawback that is relatively easily overcome. The recent introduction of audio helps offset some of the inconvenience of text only dat a entry. Lacking, however, is the type of seamless integration and support for learning and administration that will propel broad-based use with consistently demonstrated success. SecondLife is currently a very closed system with little inherent support for group support in terms of knowledge di scovery, storage and dissemination.

Beyond SecondLife itself are the issues of institutional receptivity and readiness. Institutions struggle to realize that a single product can have both gaming and educational use and that "edutainment" is a viable alternative to more traditional approaches. The end result is that SecondLife is often classified as a game and subsequently is blocked for general student access. This decision is made easier in that SecondLife is resource intensive in terms of bandwidth and only certifies a small range of graphics cards. Institutions are currently unprepared (and under-funded) to deal with these issues that quickly extend to pedagogical and strategic implications.

There are numerous limitations to our current study. Our participants were predominantly Chinese; SecondLife is predominantly Western-oriented, even though a China-town exists and participants can take on an "Asian look" if they wish to do so. Although no significant differences existed in our data relative to participant nationality, the lingering suspicion is that cultural differences do enter into aspects of use. For example, some Chinese have been taught that work and play do not mix which can be expected to affect their reaction to SecondLife. An additional serious limitation is the focus on T AM taken in this study. TAM (and T AM2) are oriented to explore acceptance of more traditional information systems that generally do not have the rich set of characteristics and emotional reaction present in SecondLife. In that sense, there are likely aspects of SecondLife that remain to be illuminated.

Directions for fut ure research include recommendations for further comparison and contrast of products other than SecondLife. Broadening the search space to include sense of presence and other relevant constructs is a high priority, as is also giving more focused attention to the impact of audio on team interactions. Further, we have embarked on adding embedded tools into SecondLife that better support the needs of interacting teams e.g., Brainstorming and voting. SecondLife provides an opportunity to give graphical life to traditional GSS, e.g., two-dimensional voting where participants can "stand" on the cell of their choice. 


\section{Conclusion}

SecondLife ushers in a new range of opport unities and considerations with respect to supporting teaching and learning. The mix of work and play in education is only beginning to be explored, especially in conjunction with team-based projects as reported in this paper. Examining the impact of SecondLife through the lens of T AM (and T AM2) and extended to consideration of aspects such as interaction and perceived enjoyment is but a first step in understanding acceptance. Results indicate that SecondLife (at least in its current incarnation) is likely to need some reincarnation priorto ascent to Nirvana. In that sense, it is a goal hoped for but yet to be attained in supporting teams. This should be seen more as the first step in a long road of development and research that, over time, can be expected to provide heightened insight and impact technology application in teaching and learning. The fut ure is challenging in this regard.

\section{References}

Agarwal, R., \& Prasad, J. ( 1997). The role of innovation characteristics and perceived voluntariness in the acceptance of information technologies. Decision Sciences, 28(3), 557-582.

Alavi, M., Yoo, Y., \& Vogel, D. (1997). Using information technology to add value to management education. Academy of Management Journal, 40(6), 1310-1333.

Bhattacherjee, A. (2001). Understanding information systems continuance: An expectation-confirmation model. MIS Quarterly, 25(3), 351-370.

Davis, F. D. (1989). Perceived usefuln ess, perceived ease of use, and user accept ance of in form ation technology. MIS Quarterly, 13(3), 319-340.

Dean, D., Lee, J., Orwig, R., \& Vogel, D. (1995). Technological support for group process modeling. Journal of $M I S, 11(3), 43-64$.

Dean, D. L., Orwig, R. E, \& Vogel, D. R. (2000). Facilitation methods for collaborative modeling tools. Group Decision and Negotiation, 9(2), 109-128.

Dennis, A., George, J., Jessup, L., Nunamaker, J., \& Vogel, D. (1988). Information technology to support electronic meetings. MIS Quarterly, 12(4), 591-624.

DeSanctis, G., \& Gallupe, R. B. (1987). A foundation for the study of group support systems. Management Science, 33(5), 589-609.

Fishbein, M., \& Ajzen, I. (1975). Belief, attitude, intention and behavior: An introduction to theory and research. Reading, MA: Addison-Wesley.

Gefen, D., Karahanna, E., \& Straub, D. (2003). Trust and T AM in online shopping: An integrated model. MIS Quarterly, 27(1), 51-90.

Genuchten, M., \& Vogel, D. (2007). Getting real in the classroom. IEEE Computer, 40(10), 106-108.

Genuchten, M., Vogel, D., Rutkowski, A., \& Saunders, C. (2005). HKNET: Instilling realism into the study of emerging trends. Communications of the AIS, 15, 357-370. Retrieved from http://cais.isworld.org/contents. asp

Gri ffith, T., Sawyer, J., \& Neale, M. (2003). Virtualness and knowledge in teams: Managing the love triangle of organi zations, individuals, and information technology. MIS Quarterly, 27(2), 265.

Grudin, J. (1991). CSCW. Communications of the ACM, 34(12), 30-34.

Ha, I., Yoon, Y., \& Choi, M. (2007). Determinants of adoption of mobile games under mobile broadband wireless access environment. Information \& Management, 44, 276-286.

Hobbs, M., Gordon, M., \& Brown, E. (2006). A virtual world environment for group work. FORMATEX

Hsu, C.L., and Lu, H.P. (2004). Why do people play on-line games? An extended TAM with social influences and flow experience, Information \& Management, (41), 853-868. 
Hu, P., Chau, P., Sheng, L., \& Tam, K. (1999). Examining the technology accept ance model using physician acceptance of telemedicine technology. Journal of Management Information Systems, 16(2), 91112.

Hughes, C., \& Moshell, E. (1997). Shared virtual worlds for education: The ExploreNet experiment, ACM Multimedia, 5(2), 145-154.

Hwang, Y. (2005). Investigating enterprise systems adoption: Uncertainty avoidance, intrinsic motivation, and the technology accept ance model. European Journal of Information Systems, 14, 150-161.

Kanaw attanachai, P., \& Yoo, Y. (2007). The impact of knowledge coordination on virtual team performance over time. MIS Quarterly, 31(4), 783-808.

Kou faris, M. (2002). Applying the technology acceptance model and flow theory to online consumer behavior. Information Systems Research, 13(2), 205-223.

Kwok, R., Ma, J., \& Vogel, D. (2002). Assessing GSS and facilitation effect on knowledge acquisition. Journal of MIS, 19(3), 185-229.

Legris, P., Ingham, J., \& Collerette, P. (2003). Why do people use information technology? A critical review of the Technology Accept ance Model. Information \& Management, 40, 191-204.

Lou, H., Luo, W., \& Strong, D., (2000). Perceived critical mass effect on groupware acceptance. European Journal of Information Systems, 9, 91-103.

Lucas, H. C., \& Spitler, V. K. (1999). Technology use and performance: A field study of broker workstations. Decisions Sciences, 30(2), 291-311.

Lu, M., Watson-Manheim, M., Chudoba, K., \& Wynn, E. (2006). Virtuality and team performance: Understanding the impact of variety of practices. Journal of Global Information Technology Management, 9(1), 4-23.

Mathieson, K. (1991). Predicting user intentions: Comparing the Technology Acceptance Model with the theory of plann ed behavior. Information Systems Research, 2(3), 173-191.

Maznevski, M. L., \& Chudoba, K. M. (2000). Bridging space over time: Global virtual team dynamics and effectiveness. Organization Science, 11(5), 473-492.

Mellarkod, V., Appan, R., Jones, D. R., \& Sherif, K. (2007). A multi-level analysis of factors affecting software dev elopers' intention to reuse softw are ass ets: An empirical investigation. Information \& Management, 44, 613-625.

Nunamaker, J., Briggs, R., Mittleman, D., Vogel, D., \& Balthazard, P. (1997). Lessons from a dozen years of group support systems research: A discussion of lab and field findings. Journal of MIS, 13(3), 163207.

Piccoli, G., \& Ives, B. (2003). Trust and the unintended effects of beh avior control in virtual teams. MIS Quarterly, 27(3), 365-395.

Qureshi, S., Liu, M., \& Vogel, D. (2006). The effects of electronic collaboration in distributed project management. Group Decision and Negotiation, 15(1), 55-75.

Robey, D., Khoo, H. M., \& Powers, C. (2000). Situated learning in cross-functional virtual teams. IEEE Transactions on Professional Communication, 43(1), 51-66.

Rutkowski, A., Vogel, D., Bemelmans, T., \& Genuchten, M. (2002). Group support systems and virtual collaboration: The HKNET Project. Group Decision and Negotiation, 11(2), 101-125.

Rutkowski, A., Saunders, C., Vogel, D., \& Genuchten, M. (2007). Is it already 4 AM in your time zone? Focus immersion and temporal dissociation in virtual teams. Small Group Research, 38, 98-129.

Saunders, C., Van Slyke, C., \& Vogel, D. (2004). My time or yours? Managing time visions in global virtual teams. Academy of Management Executive, 18(1), 19-31. 
Stahl, G. (2006). Group cognition: Computer support for building collaborative knowledge. Cambridge, Massachusetts: MIT Press.

Szajna, B. (1996). Empirical evaluation of the revised technology acceptance model. Management Science $42(1), 85-92$.

Taylor, S., \& Todd, P. (1995). Understanding information technology usage: A test of competing models. Information Systems Research, 6(2), 144-176.

Valaci ch, J., George, J., Nunamaker, J., \& Vogel, D. (1994). Physical proximity effects on computermediated idea generation. Small Group Research, 25(1), 83-104.

Venkatesh, V., \& Morris, M. (2000). Why don't men ever stop to ask for directions? Gender, social influence, and their role in technology acceptance and usage behavior. MIS Quarterly, 24(1), 115-139.

Vogel, D., Nunamaker, J., Martz, W., Grohowski, R., \& McGoff, C. (1990). Electronic meeting system experience at IBM. Journal of MIS, 6(3), 25-43.

Vogel, D., Genuchten, M., Lou, D., van Eekhout, M., Verveen, S., \& Adams, T. (2001). Exploratory research on the role of national and professional cultures in a distributed learning project. IEEE Transactions on Professional Communication, 44(2), 114-125.

Wu, J., \& Liu, D. (2007). The effects of trust and enjoyment on intention to play online games. Journal of Electronic Commerce Research, 8(2), 128-140.

\section{Appendix: Online Survey}

The aim of this survey is to study the technologies you (as well as your virtual team) use to support virtual team interaction during the HKNet project.

Please mark your response for all propositions for 5 technologies: Instant Messaging (MSN), Second Life (SL), Video Conferencing (VC), Forums and Email. The following definitions apply:

- Virtual Team: A group composed of both Hong Kong and Netherlands members working together.

- Forums: the discussions associated with your virtual team area in Blackboard.

The results of this survey will help us asse ss learning environment support and development for extended student use and may be used in academic papers. All your responses will be kept confidential. Thank you for your participation!

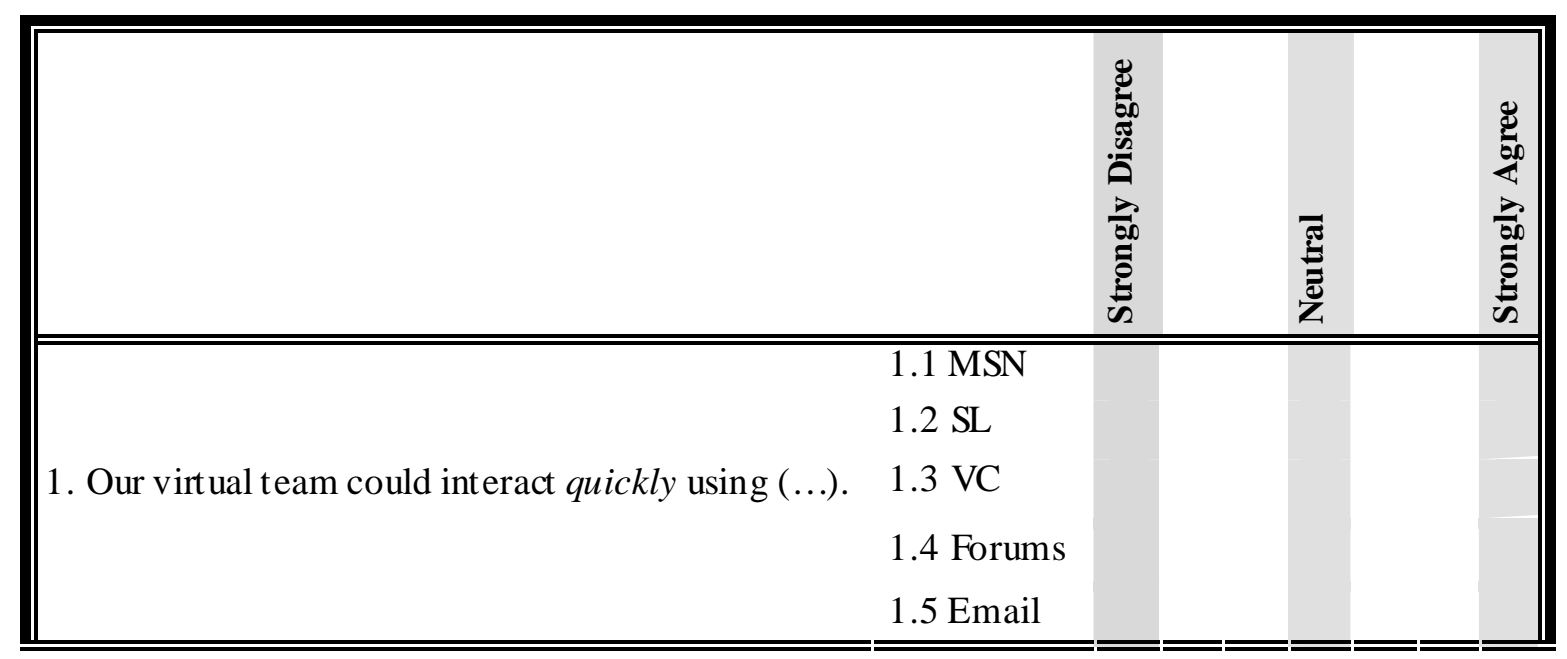




\begin{tabular}{|c|c|}
\hline 2. Our virtual team could interact easily using (...). & $\begin{array}{l}\text { MSN } \\
\text { SL } \\
\text { VC } \\
\text { Forums } \\
\text { Email }\end{array}$ \\
\hline $\begin{array}{l}\text { 3. (...) enhances/enhance our virtual team effective- } \\
\text { ness in interacting. }\end{array}$ & $\begin{array}{l}\text { MSN } \\
\text { SL } \\
\text { VC } \\
\text { Forums } \\
\text { Email }\end{array}$ \\
\hline $\begin{array}{l}\text { 4. Our virtual team could interact efficiently using } \\
\text { (...). }\end{array}$ & $\begin{array}{l}\text { MSN } \\
\text { SL } \\
\text { VC } \\
\text { Forums } \\
\text { Email }\end{array}$ \\
\hline 5. Learning to use (...) was easy for our virtual team. & $\begin{array}{l}\text { MSN } \\
\text { SL } \\
\text { VC } \\
\text { Forums } \\
\text { Email }\end{array}$ \\
\hline $\begin{array}{l}\text { 6. Our virtual team found it easy to use (...) to inter- } \\
\text { act. }\end{array}$ & $\begin{array}{l}\text { MSN } \\
\text { SL } \\
\text { VC } \\
\text { Forums } \\
\text { Email }\end{array}$ \\
\hline $\begin{array}{l}\text { 7. It was easy for our virtual team to become skilful } \\
\text { at using (...). }\end{array}$ & $\begin{array}{l}\text { MSN } \\
\text { SL } \\
\text { VC } \\
\text { Forums } \\
\text { Email }\end{array}$ \\
\hline $\begin{array}{l}\text { 8. Overall, our virtual team believes (...) was/were } \\
\text { easy to use. }\end{array}$ & $\begin{array}{l}\text { MSN } \\
\text { SL } \\
\text { VC } \\
\text { Forums } \\
\text { Email }\end{array}$ \\
\hline
\end{tabular}




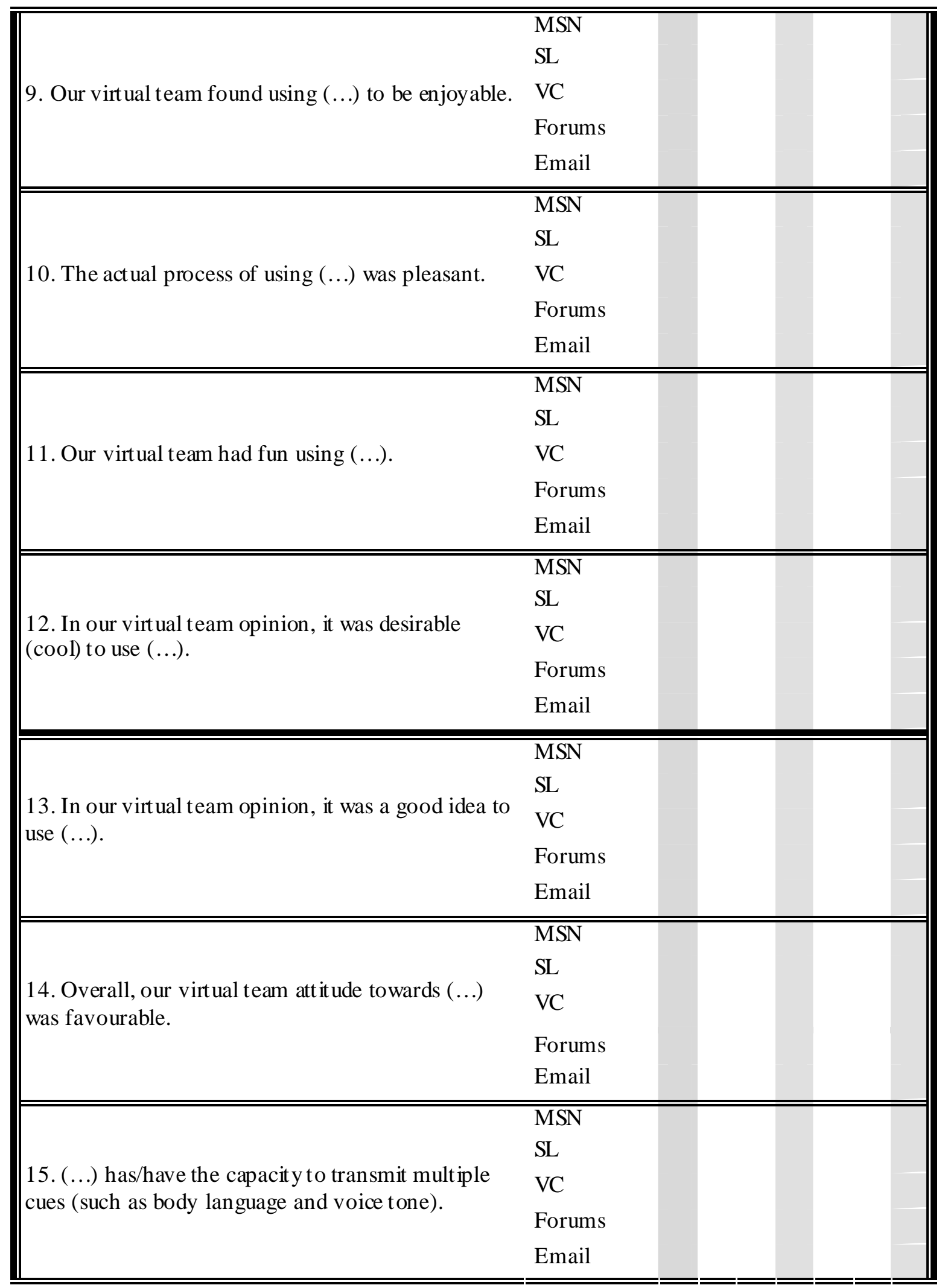




\begin{tabular}{|c|c|}
\hline $\begin{array}{l}\text { 16. (...) has/have the capacity to transmit emotions } \\
\text { (such as anger, happiness, and excitement). }\end{array}$ & $\begin{array}{l}\text { MSN } \\
\text { SL } \\
\text { VC } \\
\text { Forums } \\
\text { Email }\end{array}$ \\
\hline $\begin{array}{l}\text { 17. (...) has/have good functionality relevant to in- } \\
\text { teraction. }\end{array}$ & $\begin{array}{l}\text { MSN } \\
\text { SL } \\
\text { VC } \\
\text { Forums } \\
\text { Email }\end{array}$ \\
\hline $\begin{array}{l}\text { 18. (...) has/have (an) appropriate style of design } \\
\text { (e.g. an attractive interface) for interaction. }\end{array}$ & $\begin{array}{l}\text { MSN } \\
\text { SL } \\
\text { VC } \\
\text { Forums } \\
\text { Email }\end{array}$ \\
\hline $\begin{array}{l}\text { 19. Our virtual team did NOT schedule the use of } \\
\text { (...). }\end{array}$ & $\begin{array}{l}\text { MSN } \\
\text { SL } \\
\text { VC } \\
\text { Forums } \\
\text { Email }\end{array}$ \\
\hline $\begin{array}{l}\text { 20. Our virtual team paid much attention to schedule } \\
\text { the use of }(\ldots) \text {. }\end{array}$ & $\begin{array}{l}\text { MSN } \\
\text { SL } \\
\text { VC } \\
\text { Forums } \\
\text { Email }\end{array}$ \\
\hline 21. Our virtual team tightly scheduled the use of $(\ldots)$ & $\begin{array}{l}\text { MSN } \\
\text { SL } \\
\text { VC } \\
\text { Forums } \\
\text { Email }\end{array}$ \\
\hline 22. Our virtual team used (...) only when planned. & $\begin{array}{l}\text { MSN } \\
\text { SL } \\
\text { VC } \\
\text { Forums } \\
\text { Email }\end{array}$ \\
\hline
\end{tabular}




\begin{tabular}{|c|c|}
\hline $\begin{array}{l}\text { 23. I plan to use (...) during the remainder of the pro- } \\
\text { ject. }\end{array}$ & $\begin{array}{l}23.1 \mathrm{MSN} \\
23.2 \mathrm{SL} \\
23.3 \mathrm{VC} \\
23.4 \text { Forums } \\
23.5 \text { Email }\end{array}$ \\
\hline $\begin{array}{l}24 . \mathrm{I} \text { intend to continue using }(. . .) \text { during the re- } \\
\text { mainder of the project. }\end{array}$ & $\begin{array}{l}\text { MSN } \\
\text { SL } \\
\text { VC } \\
\text { Forums } \\
\text { Email }\end{array}$ \\
\hline 25. In my opinion, it is desirable (cool) to use (...). & $\begin{array}{l}\text { MSN } \\
\text { SL } \\
\text { VC } \\
\text { Forums } \\
\text { Email }\end{array}$ \\
\hline
\end{tabular}

\section{Personal Information}

Student ID:

Your Gender:
A. Male
B. Female

Your Age:

A. $18-21$

B. $22-25$

C. $26-29$

D. $>29$

Your Work Experience (years): A. 0

B. 1-2

C. 3-4

D. $>4$

Your Location:

Your Nationality:

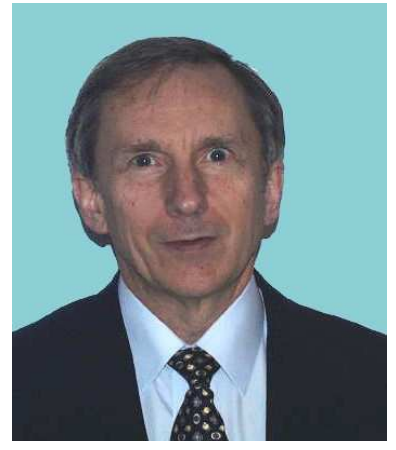

A. Hong Kong

B. The Netherlands
A. Mainland China
B. Hong Kong, China
C. The Netherlands
D. Other

\section{Biographies}

Doug Vogel is Professor (Chair) of Information Systems and an AIS Fellow. He has published widely and directed extensive research on group support systems, knowledge management and technology support for education. His research interests bridge the business and academic communities in addressing questions of the impact of information systems on aspects of interpersonal communication, group problem solving, cooperative learning, and multi-cultural team productivity and knowledge sharing. Additional detail can be found at $\underline{\text { http://www.is.cityu.edu.hk/staff/isdoug/cv/ }}$ 


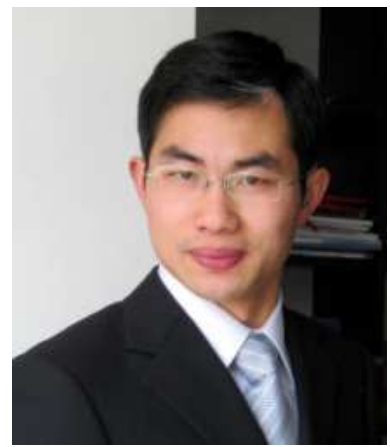

Xitong (Maxwell) Guo is a Ph.D. student in the joint program between CityU (City University of Hong Kong) and USTC (University of Science and Technology, China). He is part of the Knowledge Management and Innovation Research Group in the CityU/USTC Research Center, SIP (Suzhou Industry Park). His research interest s include information sharing issues in supply chain management and social computing.

Zhongyun (Phil) Zhou received his B.A. in Management Science from USTC and is currently a PhD student in the UST C-CityU Joint Advanced Research Center, a collaborative scheme for PhD student supervision sponsored by the University of Science and Technology of China (USTC) and the City University of Hong Kong (CityU). His current research interests include the adoption and utilization of new information technology (IT) applications and the roles and strategic value of IT for managing knowledge in distributed work groups.

Wen (Stella) Tian earned her undergraduate degree in Management Science from the University of Science and Technology of China (USTC). She is currently studying at the USTC-CityU Joint Advanced Research Center towards a PhD in Information Systems. She has taken part in research and consultant projects such as Chinese Virtual World Adoption and Diffusion, Short Term Behavior in Chinese Scientific Community and Strategies on Compensation \& Culture of Huishang Metal Co., Ltd. and published accordingly.

Xi (Jacky) Zhang received a Bachelor degree from the University of Science and Technology of China (UST C). He is enrolled in the joint PhD program bet ween USTC and City University of Hong Kong (CityU). At present he is aPhD candidate in the department of Information Systems at CityU. His research focuses on soft ware development management, distributed work, and knowledge management in Chinese enterprises. 